\title{
Applying an emphatic design model to gain an understanding of consumers' cognitive orientations and develop a product prototype
}

\author{
Ding-Bang Luh ${ }^{1}$, Chia-Hsiang Ma ${ }^{1}$, Ming-Hsuan Hsieh ${ }^{1}$, Cheng-Yong Huang ${ }^{2}$ \\ ${ }^{1}$ National Cheng Kung University, ${ }^{2}$ Kao Yuan University (TAIW AN, ROC) \\ lubdb@,mail.ncku.edu.tw; yufen@,mail.ncku.edu.tw; magicjack.24@gmail.com;.yong@,cc.kvu.edu.tw
}

Received October 2011

Accepted February 2012

\section{Abstract:}

Purpose: Consideration of consumer opinion is a key success factor when it comes to developing a new product. However, businesses may lack suitable methods for this, and designers may lack practical training, with both situations meaning that firms are unable to precisely adopt consumer opinions. Moreover, consumer cognitions for a product are widely regarded as changeable and abstract. It is worth studying how to determine consumers' opinions and transform them into references for prototype development. The purpose of this study is thus to create an Empathic Design Model which would be able to determine consumer cognitive orientation.

Design/methodology/approach: This model includes observing related phenomena, laddering the cognition, connecting the elements of the Associations Matrix, producing the hierarchy of the following four items, attributes, functional consequences, psychosocial consequences and values, and then producing a prototype to help designers and consumers reach a consensus on the cognitive structure of products.

Findings: As demonstrated in a case study of the design of an "electronic tour guide", the authors developed a prototype that can help a guide to perform their job on a group package tour. Consequently, the Empathic Design Model can be 
operated and put into practice. By Mind Mapping, the prototype can be then imitated and reinvented by designers as needed.

Originality/value: This model focuses on the early phase of the design process, providing the designing industry with a technique to forecast consumers' potential needs and develop a prototype effectively.

Keywords: empathic design, consumer demand, cognitive structure, product prototypes, demand forecasting

\section{Introduction}

The key to deciding if a product is successful in the marketplace is whether or not it meets consumer demands and preferences, rather than whether there is a breakthrough in technology (Baxter, 1995). For modern businesses, the real competitive advantage lies in providing what consumers are looking for rather than what businesses are good at providing. The explosion of product variety may generate information overload and lead to customers who are highly heterogeneous in their willingness and ability to interact with businesses (Miceli, Ricotta \& Costabile, 2007). Kleef, Trijp and Luning (2005) mentioned that in the initial process of new product development, listening to consumers is undoubtedly a key to success. However, this step has long been ignored or worked questionably for most businesses. Ulwick (2002) noted the often-heard argument that asking consumers what they need is useless, because they do not know what they need. However, although they may not be able to articulate what they need, understanding how consumer needs are shaped and influenced is still very important in ensuring that potentially used product concepts are not ignored.

A consumer has feelings toward a product because the product has meaning to the consumer, and this meaning is generated by cognition: the evaluation as to whether or not a product will be bought (Gutman, 1982; Zanoli \& Naspetti, 2002). Therefore, designers not only design a product, but also the related consumer cognition. When it comes to product cognition, the designer's interpretations do not necessarily match the consumers' desires, and many products which are successful from a designer's perspective have not sold well in the marketplace, meaning that here was a gap between designers' and consumers' cognition models (Chuang, Chang \& Hsu, 2001). In other words, the meaning of a product to consumers is not 
necessarily the same as its meaning to designers. In an era of product diversification, designers should thus not analyze consumers' demands and preferences solely based on their own professional and internalized thought processes.

The product-centric approach faces certain challenges to success that can be overcome by the consumer-centric approach (Jain \& Singh, 2002). A fuller understanding of consumer cognition and a careful observation of consumer behavior are necessary for good design, and in this regard empathic design is a consumer-centric design process that emphasizes the observation of the various phenomena that emerge when consumers use products or services. It can be used to apply the results gained from an analysis of the emotional aspects of using a product or service to new product development. In contrast to traditional research that focuses on well-understood products or services, empathic design concentrates on observing consumers' daily lives, and thus is able to gather the following hardto-find information (Leonard \& Rayport, 1997): triggers of use, interactions with the user's environment, user customization, intangible attributes of the product and unarticulated user needs. Lofthouse, Bhamra and Burrow (2005) applied empathic design to one textile manufacturer, Tencel Ltd. When this firm called for employee feedback on its current product lines, and thus obtained greater understanding of correct and incorrect features, the managers immediately decided to improve the related work areas. Kouprie \& Visser (2009) proposed a framework that could be applied in design practice, with empathic design appearing in four phases: discovery, immersion, connection and detachment. Discovery means entering the consumer's world, immersion means adopting the consumer's point of reference, connection means achieving emotional resonance and finding meaning, while detachment means designing from a user's perspective. However, although it is widely believed that consumers' needs are important and there are various techniques to survey these, both a fundamental understanding of empathic design and a framework for how to apply it to product prototypes are still lacking in the design industry. This study thus attempts to establish an Empathic Design Model (EDM) to gather, select, analyze and make use of feedback from consumers, forming a design guideline in the initial stage of product development.

\section{Background}

The major task of EDM is to understand consumers' cognitive orientations and gain insight into the cognitive structure of consumers' impressions of the product. Useful information extracted from consumers' needs is then used to develop a 
prototype. Therefore, the following review of the literature is aimed at exploring relevant studies on consumer cognition, product prototypes and empathic design as a basis for developing an EDM.

\subsection{Consumer cognition}

Armstrong and Kotler (2000) postulated that cognition is the process of consumers' selecting, organizing and interpreting of external information and transforming it into internal information. Its main focus is the type of information and the method of processing it. Here, information means something stored in human memories, while processing methods refers to acquiring, storing and using that information. In Schiffman and Kanuk (2000) definition, the process of cognition includes stimuli, sensory receptors, attention, interpretation, response and reception. In the early phases of the cognitive process, stimuli, sensory receptors and attention are all related to sensation, with the sensory system receiving external stimuli and reacting immediately. In the later phases, interpretation, response and reception, the sensory system explains sensations and converts them to perceptions. Sensation is a simple psychological process based on physiology which can be explored through observation. In contrast, perception is a complicated psychological process which can be explored through in-depth interviews. Sensation and perception are a series of psychological activities. When consumers decide to buy a product, the intrinsic messages of the product can be sensed through the sensory system, integrating extrinsic messages to form perception. Perception then influences consumer attitudes and behaviors. Intrinsic messages include the functions, materials and the appearance of products, while extrinsic ones include the prices, brands and guarantees.

\subsection{Product prototypes}

In order to meet various purposes, prototypes come in many forms. Jordan (1998) pointed out that in a cycle of design and evaluation there are a number of distinct prototyping options. Examples of these options are verbal or written descriptions of product appearance and functions, physical representations on paper or screen, product models, screen-based interactive prototypes and fully working objects. In terms of the principal stages of a design process, Stanton and Young (1999) divided prototypes into concept, design, analytical prototype, structural prototype and operational prototype. Ullman (2003) described four different kinds of prototypes based on their functions and their process of product development. In the initial stage, a proof-of-concept prototype lets a firm know what kind of product it will design. Second, the proof-of-product prototype embodies the design and 
clarifies production feasibility. Third, the proof-of-process prototype can represent the methods and materials associated with a successful design. Lastly, the proofof-production prototype proves that the whole manufacturing process is effective.

In this study, prototype is defined as a proof-of-concept prototype, referring to nuclear design concepts and features which can then be extended. The main aims with this kind of prototype are to clarify product functions and configurations, as well as its practical uses, thereby helping to indicate a correct direction for product development. A good prototype is designed within clear limitations, helping development personnel to more easily understand the desired features of the product and thus engage in meaningful group discussions, leading to the development of improved products and shortening the time to market.

\subsection{Emphatic design}

Leonard and Rayport (1997) proposed the empathic design process includes five steps.

- Step 1: Observation. Who should be observed, who should do the observing, what the observer should be watching?

- Step 2: Capturing data. Use photography or videography as tools to store and convey data that might otherwise be omitted. Empathic design stresses accompanying inquiry to observe consumers, asking open-ended questions like "Why are you doing that?" The useful information gathered after screening will be much less than the original information.

- Step 3: Reflection and analysis. After gathering information in various forms, team members should think what they have observed, and review all the visual data with each other.

- Step 4: Brainstorming for solutions. Inspiration is the most valuable part in any innovation process. In the process of empathic design, inspiration is specifically used by transforming observations into graphics, and it uses visual representations to present possible solutions.

- Step 5: Developing prototypes of possible solutions. Prototypes specifically clarify the appearance and features of products or services as well as how they are used. This helps the discussion with potential consumers. 
Empathic design understands consumers mainly through observation and inquiry; however, this method has the following weaknesses (Deszca, Munro \& Noori, 1999; Evans \& Burns, 2007):

- A considerable amount of the researchers' time is wasted. This is because they must clarify who should be observed and what behavior should be watched, and enter the actual observation environment to continuously record the daily behavior of consumers to find any hidden demands. Relative to traditional research, empathic design thus undoubtedly is a longer and more time-consuming process.

- It has less history of implementation than traditional research. Theoretically, empathic design is feasible, but it faces some challenges when being put into practice. For example, it is not an easy task to observe consumers who do not want to be monitored, and even those that doe may show behaviors different from their usual ones when they are aware of being watched, and this leads to inaccurate data. Another challenge is that researchers need to work hard to overcome their own preconceptions and be careful not to intervene in consumers' activities.

- Researchers need to have a specific set of capabilities, such as being adept at collaborative and interdisciplinary interactions. At the same time, they need to have a good understanding of visual, spoken, and numerical data. Most important of all, they have to possess the skills required to analyze and present innovative product prototypes.

\subsection{Research questions}

Empathic design puts emphasis on participating in empathic experiences and indepth interviews to uncover consumers' unarticulated issues and needs; however, the following issues arise when it is being implemented:

- Since empathic design's five steps have not been developed into a specific and operable procedure, it takes more time to conduct a study and researchers need to have considerable experience and expertise.

- Empathic design does not define the results from each step and does not indicate how the results should be presented when moved on to the next step. This presents a number of problems, such as making the goal or task unclear and making it hard to connect between each step. 
- Researchers should not limit themselves to consumers' current cognitive structures, and instead they need to successfully draw consumers' attention to those that seem unimportant and apply effective tools to transform the data on consumer demands that they obtain into useful design information.

\section{EDM construction}

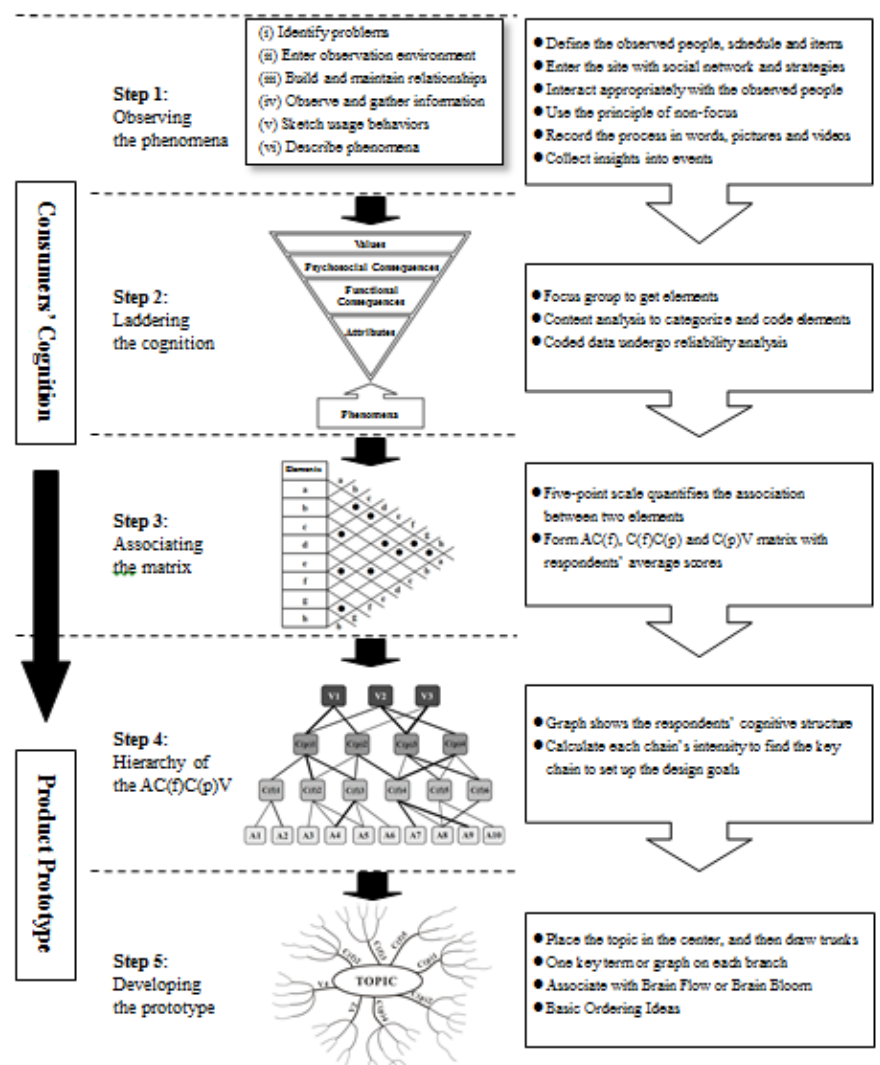

Figure 1. Empathic design model

It is difficult to understand consumer cognitive orientations through traditional market surveys, and the best way to do so is through interaction. Therefore, effectively handling observations and interviews collected in the field is necessary to understand consumer cognition, as they can help explain the meaning behind the relevant phenomena. To meet this requirement, empathic design is a new market research technique that aims to meet the needs of consumers through analysis of detailed observations. The whole process includes observation, capturing data, reflection and analysis, and brainstorming and developing prototypes of possible solutions (Leonard \& Rayport, 1997). However, due to limitations of time, budget, tools and manpower, in most design industries empathic design has rarely carried out. This study utilizes Participant Observation and a Means-End Chain for capturing data, an Associations Matrix for analysis, a 
Hierarchical Value Map to produce solutions, and Mind Mapping to develop prototypes to form an EDM (see Figure 1 ) that can survey consumer opinions and deal with different consumer needs under different circumstances.

\subsection{Method of understanding Consumer Cognitive Orientations}

In the following subsections the authors review Participant Observation, an effective method of observing activities when researchers have direct contact with consumers. Second, Laddering, a communication technique that can create good interaction with consumers and help better appreciate consumers' experiences and cognitions, is introduced. Third, an Associations Matrix, used to quantify the associations between the elements which scored by respondents, is briefly described. The results of this quantification are the basis for drawing the Hierarchical Value Map (HVM).

\section{Step 1: Participant Observation}

Kelley, Littman and Peters (2001), General Manager of the internationally renowned design firm IDEO, once noted that product innovation begins with an eye, and personal experience always wins over fiction and imagination. At IDEO, observing consumers is a necessary step in every design project initiation. Psychologists, sociologists and designers observe the interaction between consumers, products and environment. They evaluate the latent needs of consumers in regard to new products, in order to provide every possible solution. Participant Observation means researchers actually become part of the observed group and observe it from within by partaking in activities with subjects. Participant Observation is used because consumption phenomena and product definitions vary according to time and place, and are thus dynamic in nature. This method can provide direct and detailed information with regard to how phenomena occur, and allow a more thorough understanding of them. Pedgley (2007) demonstrated that Participant Observation is a suitable method for collecting and recording data in design activities. In addition, Jerrard, Barnes and Reid (2008) postulated that in new product development market needs can be determined through Participant Observation, including empathic involvement, recording and analyzing consumers' experiences.

\section{Step 2: Laddering}

The Means-End Chain entails the process of forming links among product attributes, consumption consequences and personal values. If some attribute can 
be linked to a relatively abstract value, that attribute is important (Ferran \& Grunert, 2007; Gutman, 1982; Klenosky, 2002). Olson and Reynolds (1983) then sorted this chain into six sub-levels, forming the Means-End Chain Model (see Figure 2). The Means-End Chain has since been successfully used in new product development and strategic marketing management (Gutman \& Miaoulis, 2003; Pieters, Baumgartner \& Allen, 1995).
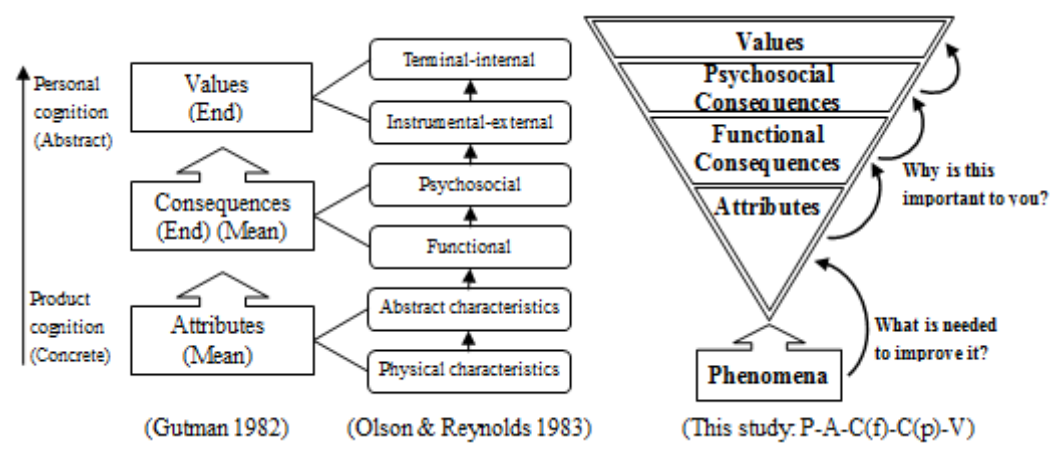

Figure 2. Comparison between Means-End Chain Model and this study

Laddering is simply a technique for collecting Means-End Chains from respondents. It uses one-on-one in-depth interviews to obtain the consumers' psychological perspectives, and is done step by step via direct elicitation (Chiu, 2005; Hofstede, Audenaert, Steenkamp \& Wedel, 1998). A typical question for Laddering is "Why is this (based on the subject's previous answer) important to you?" This inquiry process keeps being repeated until answers such as "I don't know" or "This is the way it is" show up (Reynolds \& Gutman, 1988). Reynolds and Olson (2001) cited numerous actual examples of Laddering, and from these examples we can see that most subjects first answered their questions with the more tangible attributes. If the interviewer keeps asking questions, more abstract consequences will start to show up, and finally the most abstract personal values will appear. A carefully detailed process from the lowest level (attributes) to the highest level (values) can explain the motives of consumers and how product information is being interpreted. In addition, the reasons why a certain attribute or consequence are important can be clearly prioritized.

The authors had tried to use the Means-End Chains (Gutman, 1982) on the product. The results are too sketchy, and they can not fully present the opinions of consumers. When using the classification which was proposed by Olson and Reynolds (1983). Most of the consumers can not describe the sub-levels of physical characteristics, abstract characteristics, instrumental-external and terminal-internal values in detail, but they can easily describe functional and psychosocial 
consequences. By examining many studies on Laddering (Botschen \& Hemetsberger, 1998; Fotopoulos, Krystallis \& Ness, 2003; Gengler, Mulvey \& Oglethorpe, 1999; Kuisma, Laukkanen \& Hiltunen, 2007), we can find that interrelationships at the consequences level of the Means-End Chain are complicated. Therefore, the attributes and values are retained, but the consequences are divided into "functional" and "psychosocial" aspects in this study (see Figure 2). Functional consequences are the direct experience of consumer using the product attributes. Psychosocial consequences are the psychosocial feeling arised from functional consequences, and it can be linked to personal values. The information obtained from consumer can be presented more coherently and causally by connecting concrete phenomena to abstract values. In brief, through Laddering, the MeansEnd Chain infers a cognitive structure $(P-A-C(f)-C(p)-V)$ that can not be achieved by observations alone, and is an effective method of discovering consumer motives and standards for decision-making.

\section{Step 3: Associations Matrix}

Veludo-de-Oliveira, Ikeda and Campomar (2006) argued that the Implication Matrix is a method that can bridge the gap between qualitative and quantitative findings. Reynolds and Gutman (1988) stated, "such a matrix will be a square matrix with a size reflecting the number of elements one is trying to map." Rekom and Wierenga (2002) explained that the titles of the rows and columns in the matrix are the elements. Row-items represent means, while column-items represent ends. All interactions among the elements that originate from the qualitative data are verified. Calculating the direct and indirect links among all the elements can be used to summarize the number of links mentioned by respondents (Phillips \& Reynolds, 2009). Take one Means-End Chain A-C-V as an example, A is neighboring $C$, and $C$ is neighboring $V$; these are direct relationships. However, $A$ neighbors $V$ through $C$, so there is an indirect relationship between $A$ and $V$. Unlike calculating the number of links by the Implication Matrix, this study applies a scale questionnaire that asks the respondents to score the associations between two elements. The changed Implication Matrix (Associations Matrix) carries the concept of weighting, allowing the respondents' opinions to be differentiated by levels and their opinions to be more precisely extracted.

\subsection{Method of developing prototypes}

A Hierarchical Value Map shows all the respondents' cognitive structures through its visual graphs, allowing researchers to discover important links in setting up the design goals. Mind Mapping is a tool used to trigger creative thinking, aid decision- 
making and integrate information using concrete means for developing the prototype of possible solutions, like words, symbols and sketches. These steps are discussed in more detail, below.

\section{Step 4: Hierarchical Value Map}

The HVM is used to reveal the results of Associations Matrix data analysis in a graphical form as a reference for brainstorming. It can represent the majority of the thoughts of most people, helping researchers to know more about the market. Through HVM, we can understand the overall networking relationships of a product in the Means-End Chain. In this context, "value" guides the overall directions of consumer needs, "consequence" is a specific behavior in certain circumstances, and "attribute" refers to a tangible product feature.

An HVM consists of a series of nodes, connected by lines, representing the aggregate of the respondents' ladders, and it has four important features (Kuisma et al., 2007; Parry, 2002), as follows.

- It is customer-oriented, as the central idea is to carefully analyze consumer opinions in order to help create satisfied consumers.

- The "benefits" of products are emphasized, as these are the reasons why consumers actually buy the related products or services.

- It is dynamic, in order to reflect the changing nature of consumers' cognitive structures, thus creating new connections between elements.

- It can uncover insights by interpreting information obtained from in-depth interviews with consumers in order to understand the attributes of products or services from consumers' points of view, as well as the benefits or values accompanying these.

\section{Step 5: Mind Mapping}

Mind Mapping is a good tool to help solve problems with creativity, striking a balance between science and art, creativity and logic (Buzan, 1974). Mind Mapping is a structuralized mode of radiant thinking, i.e., associating the subject with more sub-subjects. Each branch (a keyword, image or symbol) is itself a center, and each center can associate with more elements, and so on (Budd, 2004). According to Buzan and Buzan (1996), the purpose of Mind Mapping is as follows: to erase the previous assumptions of the subject and bring unlimited creative thoughts; to 
consistently create or change idea; to reorganize old thinking patterns and form new conceptual frameworks. In a brainstorming session, team thoughts can be integrated and the background knowledge that triggers critical thinking can be provided through Mind Mapping, so that the quality and quantity of ideas can be raised (Paykoç et al., 2004). Mind Mapping is able to accomplish classification and categorization of ideas according to the connections between them. In addition, it allows researchers to not only comprehensively understand the subject, but also to clearly see the relationships between details themselves as well as between details and the whole. The method has been broadly applied to knowledge management and design education (D'Antoni \& Zipp, 2006; Kokotovich, 2008; Protzman \& Raval, 2004).

Each step of EDM is closely connected. In order to discover and gather useful elements in consumers' lives and work, Participant Observation (Step 1) and Laddering (Step 2) need to be executed. Steps 3 and 4 use an Associations Matrix and HVM to transform consumer demands into useful design information, and then present visualizations of this. Mind Mapping (Step 5) is then able to present the whole proof-of-concept prototype of a new product. Consumers play a very important role during the EDM process, and this allows designers to develop products based on actual market needs.

\section{Case study}

This section presents details of a case study focusing on an electronic tour guide, with each step of the related EDM presented and explained. EDM starts with Participant Observation, and a number of images related to the group package tour (GPT) were developed in the form of phenomena cards (see Figure 3 ). There were ten cards in total, and these were used as the stimuli for the Laddering interviews with 24 participants which were divided into four focus groups. The relevant elements were acquired through Laddering interviews and coded, with 13 attribute elements, nine functional consequence elements, six psychosocial consequence elements and four value elements in total. After 91 respondents scored the associations between the elements that were arranged through the Associations Matrix, an HVM was used to present the network of the Means-End Chain, having determined the cognition of consequences and values important to consumers. Information, memory, interpersonal relations, atmosphere, happiness, comfort and safety were then used to set up the design goals, and the designers then used Mind Mapping based on these to create the prototype. 


\subsection{Observing the phenomena}

GPT is a popular type of travel, and the biggest difference between it and independent is that it has a tour guide and tour members. The tour guide is responsible for guiding the travelers and helping meet their daily needs, such as accommodating and food, as well as dealing with any health and safety issues (Ap \& Wong, 2001; Wang, Hsieh, Chou \& Lin, 2007). However, if there is only one tour guide to meet of all the needs of a group this can be very exhausting, and the goal of this case study was thus to design a prototype electronic tour guide. The details of related Participant Observation process are as follows:

- Identifying problems: A tour guide plays an important role in GPT, providing group members with both entertainment and security. It is worth noticing, as a direction for design, how the interaction between the tour guide and the group members can be improved. There are many elements linking the guide and the members, such as introducing accommodation, tourist attractions, food and medical care. It is impossible for a guide to be with the tourists all the time, and thus the electronic tour guide was primarily designed as a device to be worn around the neck with a screen, buttons and a Bluetooth connection. Members would be able to borrow them from travel agencies as communication tools.

- Entering the observation environment: The choice of environment is highly related to the questions posed. In order to know the members' needs, the researchers joined a six-day, five-night tour group to South East Asia. The researchers joined in each activity within the group, and discovered that even when in the middle of two scenic sites, most other group members were just sitting and chatting with each other.

- Building and maintaining relationships: To most people, many elements in an environment are invisible, and observation is thus not an easy task. In addition, people tend to change their behavior when they know they are being observed, and this could lead to the collection of inaccurate data. Therefore, observers should be cautious, honest and undertake no stereotyping. To make the observations as natural as possible, the researchers on this six-day trip tried to understand the tourists' lives and behaviors through interactions with them. The hope was that the travelers would thus reveal their true behavior to the researchers. 
- Observing and gathering information. It is important to stay open-minded to all incidents during an observation, as stereotyping may bias the results. Before more specific targets are aimed at, a great deal of unspecific primary observation and data collection should be done. The observation focuses should originate from the topic. In this case, the focuses included the circumstances of leisure time, chatting, guiding at tourist spots, group gatherings and other notable incidents.

- Sketching usage behaviors: To record all the interactions among the observed individuals, products, services or spaces. People's memories are not reliable, so it is necessary to record activities with words, pictures or videos. The content should include the date, place, character, behavior and researchers' feelings and speculations. For example: At 10:30 A.M on July 22,2009 , the guide gathered all the members at spot $A$. This might indicate there was something important to announce. At 2:40 P.M on July 22, 2009, member A was looking at the map on spot $B$. This could mean the member was lost or looking for a particular amusement facility.

- Describing phenomena: In this step, the focus is shifted from gathering information to screening it. Phenomena will be modified and organized based on grouping and naming pictures by researchers, and they will be interpreted using an easy-to-understand format (phenomena cards). Pictures collected through Participant Observation have been consolidated into a finite set of phenomena (see Figure 3), and these are briefly described in Figure 4.

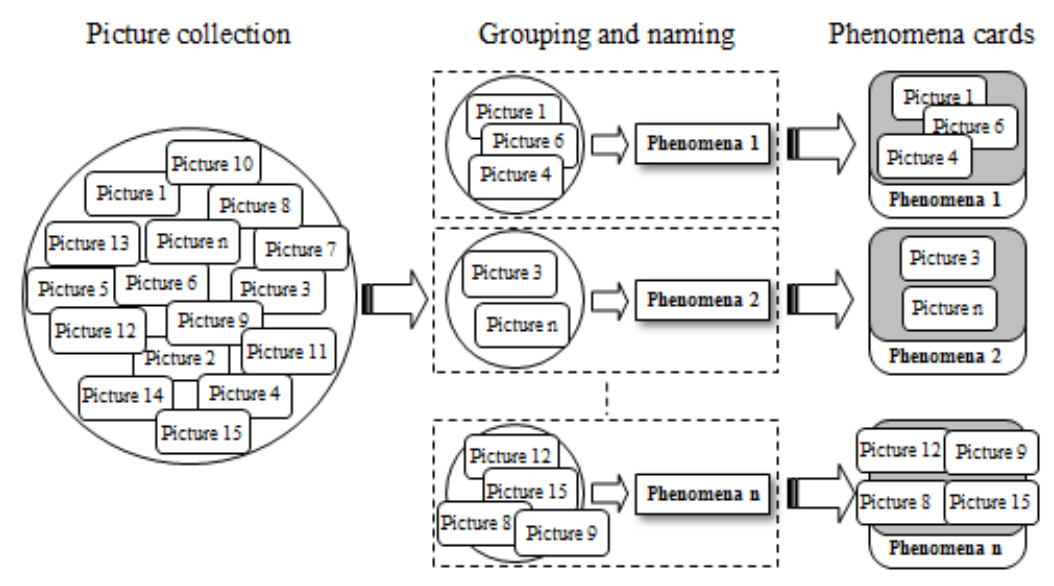

Figure 3. How to consolidate pictures collected through Participant Observation into a finite set of phenomena 


\subsection{Laddering the Cognition}

Step 2 used focus groups to elicit all the related attributes, functional consequences, psychosocial consequences and value elements $(A C(f) C(p) V)$. Each focus group contained six participants, with each person having experienced a GPT at least five times. There were four focus groups with 24 participants in this case study, because there were no more new elements seen in the fourth group.

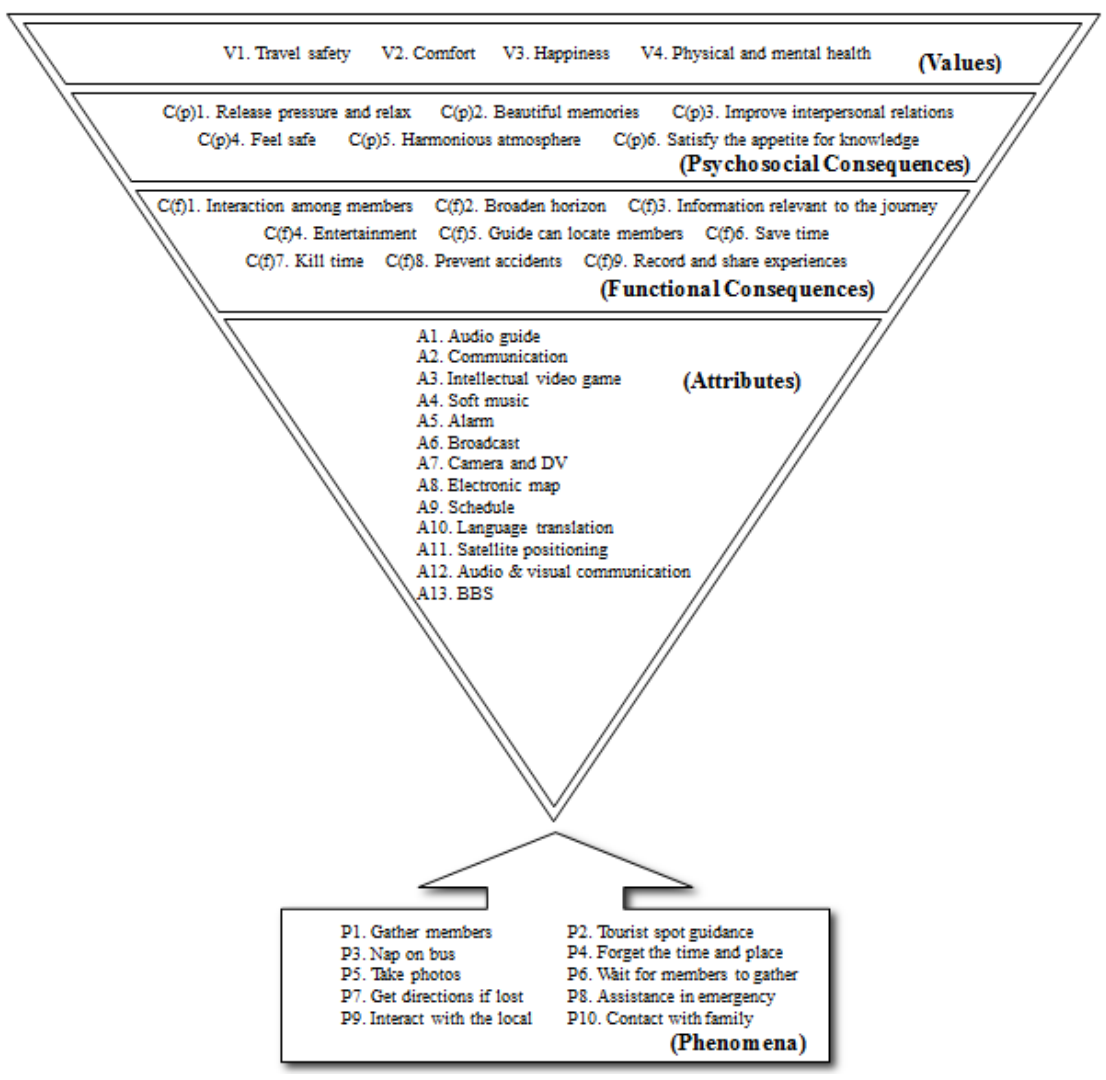

Figure 4. Summary content codes (*Consequences are categorized into $C(f)$ and $C(p)$ )

Zaltman (2003) pointed out that people's unconscious can be elicited through the pictures they choose. The participants in this study picked out phenomena cards they found important or interesting and discussed their related GPT experiences with others in their group. The moderator assisted the participants in rising the ladder of abstraction. For example, to link phenomena to attributes, a question such as "What is needed to improve it?" could be asked. To link attributes to consequences or link consequences to values, a question like "Why is this important to you?" could be utilized. In the last half of the meeting, besides acquiring elements from participants' responses, the moderator also asked the participants for any further ideas from the existing elements. For example, the values that had already been mentioned could be listed, and then the participants 
asked if any values that had not been mentioned could be linked to certain consequences. Each meeting lasted for 1.5 hours and was both audio- and videorecorded. After the meeting, the words collected were then examined via Content Analysis and classified into attributes, functional consequences, psychosocial consequences and values levels, before all-inclusive and mutually exclusive principles were used to further simplify and code the words. The first group collected 20 elements, the second group 25, with nine newly added, the third group 27, with three newly added and the fourth 23, with zero newly added, meaning that the number of groups was sufficient and the elements were saturated. The coding is shown in Figure 4.

Reliability Analysis was used for coded information. Three coders ( A, B and C) who were familiar with Means-End Chains and Content Analysis, coded and classified the elements. Mutual agreement among the three coders was used as the criteria for inter-judge reliability. Wimmer \& Dominick (2006) suggested a reliability of more than 0.9 . Reliability can be obtained through the following formula:

Reliability $=n \times($ average mutual agreement $) /\{1+[(n-1) \times$ average mutual agreement $]\}$

where $n$ represents the number of coders; mutual agreement $=(2 \times M) /(N 1+N 2)$, where $M$ is the number of questions with the same responses; $N 1$ is the number of questions coded by the first coder, and N2 is the number of questions coded by the second coder. The overall reliability was 0.959, which reaches a satisfactory level.

\subsection{Associating the Matrix}

The elements categorized in Figure 4 form the $A C(f), C(f) C(p)$ and $C(p) V$ Associations Matrix. In the beginning, the attributes were in columns and the functional consequences were in rows, forming an $A C(f)$ matrix. The respondents indicated the perceived associations with regard to each functional consequence in each attribute. The evaluation used a five-point scale. Very strongly associated was 5; strong associated, 4; average, 3; slightly associated, 2; and not associated, 1. Similarly, the $C(f) C(p)$ matrix listed functional consequences and psychosocial consequences, while in the $\mathrm{C}(\mathrm{p}) \mathrm{V}$ matrix listed the psychosocial consequences and values. The questionnaire (including $A C(f), C(f) C(p)$ and $C(p) V)$ was given to 107 respondents. The final sample was a population of 91 , giving a response rate of $85 \%$. Table 1 reveals the demographic characteristics of the respondents.

An aggregate Associations Matrix was then produced based on the data provided by the 91 respondents, as shown in Tables 2, 3 and 4. 


\begin{tabular}{|c|c|c|}
\hline Demographic characteristics & $\mathbf{N}$ & Percentage \\
\hline $\begin{array}{l}\text { Gender } \\
\text { Male } \\
\text { Female } \\
\end{array}$ & $\begin{array}{l}52 \\
39 \\
\end{array}$ & $\begin{array}{l}57.1 \% \\
42.9 \% \\
\end{array}$ \\
\hline $\begin{array}{l}\text { Age } \\
18-25 \\
26-35 \\
36-45 \\
46-55 \\
56-65 \\
\text { Over } 65 \\
\end{array}$ & $\begin{array}{r}23 \\
29 \\
16 \\
12 \\
9 \\
2 \\
\end{array}$ & $\begin{array}{r}25.3 \% \\
31.9 \% \\
17.6 \% \\
13.2 \% \\
9.9 \% \\
2.2 \% \\
\end{array}$ \\
\hline $\begin{array}{l}\text { Education } \\
\text { Elementary school/Junior high school } \\
\text { Senior high school/Vocational school } \\
\text { Junior college } \\
\text { University } \\
\text { Master } \\
\text { PhD }\end{array}$ & $\begin{array}{r}3 \\
14 \\
12 \\
44 \\
15 \\
3 \\
\end{array}$ & $\begin{array}{r}3.3 \% \\
15.4 \% \\
13.2 \% \\
48.4 \% \\
16.5 \% \\
3.3 \% \\
\end{array}$ \\
\hline $\begin{array}{l}\text { Profession } \\
\text { Managerial position } \\
\text { Middle management } \\
\text { Entrepreneur } \\
\text { Specialist } \\
\text { Employee } \\
\text { Student } \\
\text { Retired } \\
\text { Unemployed }\end{array}$ & $\begin{array}{r}3 \\
6 \\
7 \\
10 \\
28 \\
24 \\
7 \\
6 \\
\end{array}$ & $\begin{array}{r}3.3 \% \\
6.6 \% \\
7.7 \% \\
11.0 \% \\
30.8 \% \\
26.4 \% \\
7.7 \% \\
6.6 \% \\
\end{array}$ \\
\hline $\begin{array}{l}\text { Experience with GPT } \\
\text { No experience } \\
1-3 \text { times } \\
4-6 \text { times } \\
7-9 \text { times } \\
\text { More than } 10 \text { times } \\
\text { Total }\end{array}$ & $\begin{array}{r}3 \\
25 \\
36 \\
21 \\
6 \\
91 \\
\end{array}$ & $\begin{array}{r}3.3 \% \\
27.5 \% \\
39.6 \% \\
23.1 \% \\
6.6 \% \\
100 \% \\
\end{array}$ \\
\hline
\end{tabular}

Table 1. Profile of respondents $(N=91)$

The formula for calculating the association weight of each cell in the aggregate $\mathrm{AC}(\mathrm{f})$ Associations Matrix is as follows:

$$
\overline{A_{i} C(f)_{j}}=\frac{\sum_{(i, j)-(1,1)}^{(13,9)} A_{i} C(f)_{j}}{N}
$$

where $i$ is the number of attributes, ranging from 1 to $13 ; j$ the number of functional consequences, ranging from 1 to $9 ; N$ the number of respondents, which value is $91 ; \overline{A_{i} C(f)_{j}}$ the average association rating between the attribute $i$ and the consequence $j$, ranging from 1 to 5 .

Through the Associations Matrix, all the respondents' perceived associations could be quantified, and the Step 4 HVM was drawn based on this. In addition, Tables 2, 3 and 4 sum up all the elements' "mean $\left(\bar{X} A_{i}\right)$ ratings" to further calculate the intensity of each linkage, which is discussed in more detail in the next section. 


$$
\bar{X} A_{i}=\frac{\sum_{j=1}^{9} \overline{A_{i} C(f)_{j}}}{n}
$$

Where $i$ is the number of attributes, ranging from 1 to $13 ; j$ the number of functional consequences, ranging from 1 to $9 ; n$ the total number of functional consequences, with the value of $9 ; \bar{X} A_{i}$ is the mean association rating of attribute $i$, ranging from 1 to 5 .

\begin{tabular}{|c|c|c|c|c|c|c|c|c|c|c|}
\hline Elements & $C(f) 1$ & $C(f) 2$ & $C(f) 3$ & $C(f) 4$ & $C(f) 5$ & $C(f) 6$ & $C(f) 7$ & $C(f) 8$ & $C(f) 9$ & $\bar{X} A_{i}$ (To) \\
\hline A1 & 3.09 & 4.53 & 2.37 & 3.23 & 1.70 & 3.41 & 2.96 & 2.25 & 1.88 & 2.82 \\
\hline A2 & 3.69 & 1.73 & 3.57 & 2.93 & 3.19 & 3.19 & 3.16 & 4.13 & 3.33 & 3.21 \\
\hline A3 & 2.49 & 1.80 & 1.36 & 4.15 & 1.31 & 2.10 & 3.98 & 1.46 & 1.62 & 2.25 \\
\hline A4 & 2.90 & 3.05 & 1.46 & 4.02 & 1.40 & 3.32 & 4.25 & 1.43 & 2.93 & 2.75 \\
\hline A5 & 2.89 & 1.37 & 2.60 & 1.78 & 2.90 & 4.62 & 1.33 & 3.25 & 1.44 & 2.46 \\
\hline A6 & 1.55 & 1.47 & 3.95 & 1.37 & 2.40 & 4.13 & 1.44 & 3.30 & 1.73 & 2.37 \\
\hline A7 & 3.00 & 2.80 & 2.57 & 3.51 & 1.31 & 2.14 & 3.52 & 1.30 & 4.61 & 2.75 \\
\hline A8 & 2.89 & 2.34 & 3.81 & 2.56 & 3.70 & 3.46 & 2.85 & 4.32 & 2.54 & 3.16 \\
\hline A9 & 3.51 & 1.52 & 4.31 & 1.76 & 1.88 & 3.26 & 2.78 & 2.81 & 2.81 & 2.74 \\
\hline A10 & 2.95 & 4.10 & 2.65 & 2.25 & 2.76 & 3.47 & 2.90 & 3.89 & 2.60 & 3.06 \\
\hline A11 & 2.49 & 1.45 & 1.47 & 2.05 & 4.49 & 3.32 & 2.58 & 4.38 & 1.35 & 2.62 \\
\hline A12 & 3.22 & 1.89 & 2.00 & 3.57 & 2.79 & 3.19 & 3.38 & 2.99 & 4.21 & 3.03 \\
\hline A13 & 3.43 & 2.98 & 4.42 & 3.30 & 1.38 & 2.90 & 3.27 & 2.37 & 2.77 & 2.98 \\
\hline $\begin{array}{c}\bar{X} C(f)_{i} \\
\text { (From) }\end{array}$ & 2.93 & 2.39 & 2.81 & 2.81 & 2.40 & 3.27 & 2.95 & 2.91 & 2.60 & \\
\hline
\end{tabular}

Table 2. Associations Matrix summary for the electronic tour guide design study

\begin{tabular}{|c|c|c|c|c|c|c|c|}
\hline Elements & $C(p) 1$ & $C(p) 2$ & $C(p) 3$ & $C(p) 4$ & $C(p) 5$ & $C(p) 6$ & $\bar{X} C(f)_{i}$ (To) \\
\hline$C(f) 1$ & 3.43 & 3.54 & 4.49 & 3.29 & 4.34 & 2.30 & 3.57 \\
\hline$C(f) 2$ & 3.53 & 4.14 & 2.93 & 2.48 & 1.81 & 4.69 & 3.26 \\
\hline$C(f) 3$ & 2.16 & 3.85 & 1.54 & 4.44 & 3.14 & 3.38 & 3.09 \\
\hline$C(f) 4$ & 4.48 & 3.44 & 3.29 & 2.33 & 3.48 & 2.07 & 3.18 \\
\hline$C(f) 5$ & 1.40 & 1.69 & 2.47 & 4.36 & 2.95 & 1.97 & 2.47 \\
\hline$C(f) 6$ & 3.42 & 3.57 & 2.78 & 3.47 & 4.38 & 1.64 & 3.21 \\
\hline$C(f) 7$ & 4.16 & 3.09 & 2.21 & 2.86 & 3.47 & 2.14 & 2.99 \\
\hline$C(f) 8$ & 3.41 & 3.55 & 1.95 & 4.73 & 3.99 & 1.47 & 3.18 \\
\hline$C(f) 9$ & 3.04 & 4.57 & 3.51 & 1.75 & 3.46 & 2.17 & 3.08 \\
\hline $\begin{array}{l}\bar{X} C(p)_{i} \\
\text { (From) }\end{array}$ & 3.23 & 3.49 & 2.80 & 3.30 & 3.45 & 2.43 & \\
\hline
\end{tabular}

Table 3. Associations Matrix summary for the electronic tour guide design study

\begin{tabular}{|l|c|c|c|c|r|}
\hline Elements & V1 & V2 & V3 & V4 & $\bar{X} C(p)_{i}$ (To) \\
\hline $\mathrm{C}(\mathrm{p}) 1$ & 2.21 & 3.49 & 4.36 & 4.64 & 3.68 \\
\hline $\mathrm{C}(\mathrm{p}) 2$ & 3.44 & 4.05 & 4.57 & 3.48 & 3.89 \\
\hline $\mathrm{C}(\mathrm{p}) 3$ & 3.75 & 3.57 & 4.22 & 4.14 & 3.92 \\
\hline $\mathrm{C}(\mathrm{p}) 4$ & 4.60 & 1.96 & 3.18 & 3.13 & 3.22 \\
\hline $\mathrm{C}(\mathrm{p}) 5$ & 3.66 & 4.54 & 3.51 & 3.45 & 3.79 \\
\hline $\mathrm{C}(\mathrm{p}) 6$ & 1.46 & 1.65 & 4.08 & 3.32 & 2.63 \\
\hline $\bar{X} V_{i}$ & $\mathbf{3 . 1 9}$ & $\mathbf{3 . 2 1}$ & $\mathbf{3 . 9 9}$ & $\mathbf{3 . 6 9}$ & \\
$($ From $)$ & & &
\end{tabular}

Table 4. Associations Matrix summary for the electronic tour guide design study 


\subsection{Hierachy of the $A C(f) C(p) V$}

The $A-C(f)-C(p)-V$ Associations Matrix can be shown in the form of a tree diagram, which is the HVM. However, it would be too complicated and the important linkage could not be shown if all the elements' associations were drawn into the HVM. To maintain the balance between detail and interpretability, the authors referred to Nielsen's (1993) five-point scale. Specifically, if the mean is more than 3.60, the score will be positive, meaning significantly associated. Figure 5 shows the links with a mean above 3.60. To make the discussion and reading easier, lines of different thickness show associations of different strength between the elements. In this case, for a score $3.60-3.80$ the line is $0.75 \mathrm{pt}$; for $3.81-4.00,1.25 \mathrm{pt}$; for 4.01-4.20, 1.75p; for 4.21-4.40, 2.25pt; for 4.41-4.60, 2.75pt, and for any score more than $4.61,3.25 \mathrm{pt}$. Graphs can help designers clarify their thinking and simplify communication with others.

In the HVM shown in Figure 5, 53 complete Means-End Chains can be seen. Each chain's intensity can be obtained by referring to Tables 2,3 and 4 and summing up the "From and To" values of every element in each chain. For example, for the chain $A 1 \rightarrow C(f) 2 \rightarrow C(p) 6 \rightarrow V 3$, the "From" value for $A 1$ is 0 and its "To" value is 2.82. The "From" value for $C(f) 2$ is 2.39 and its "To" value is 3.26 . The "From" value for $C(p) 6$ is 2.43 and its "To" value is 2.63. The "From" value for V3 is 3.99 and its "To" value is 0 . Therefore, the strength of this chain is:

$$
(0+2.82)+(2.39+3.26)+(2.43+2.63)+(3.99+0)=17.52
$$

Table 5 shows the top five chains with the highest intensity out of the total of 53 . The most important chain is $A 8 \rightarrow C(f) 3 \rightarrow C(p) 2 \rightarrow V 3$, with an intensity of 20.43, which can be called a critical path. This demonstrates that the respondents regarded the "electronic map" attribute as important, and hoped that via this attribute they could get "information relevant to this journey", have "beautiful memories" and ultimately feel "happiness". To define the related goals, designers can simplify the HVM in Figure 5 if needed. Figure 6 shows that the top five chains should be taken into consideration first. 


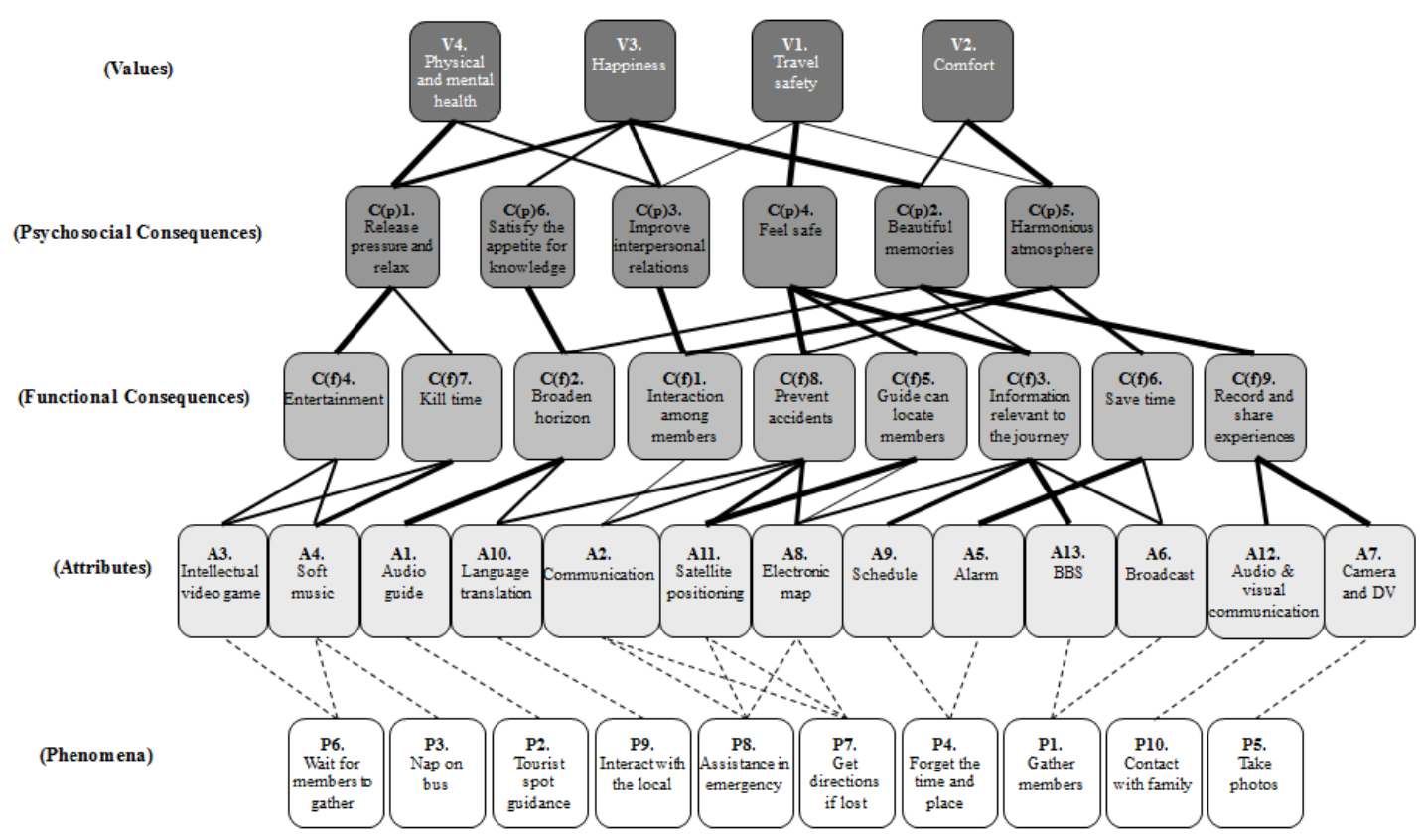

Figure 5. Hierarchical Value Map for electronic tour guide design

\begin{tabular}{|l|l|r|}
\hline Chain & "From" and "To" values for elements & \multicolumn{1}{c|}{ Strength } \\
\hline$A 8 \rightarrow C(f) 3 \rightarrow C(p) 2 \rightarrow V 3$ & $(0+3.16)+(2.81+3.09)+(3.49+3.89)+(3.99+0)$ & 20.43 \\
\hline$A 2 \rightarrow C(f) 1 \rightarrow C(p) 3 \rightarrow V 3$ & $(0+3.21)+(2.93+3.57)+(2.80+3.92)+(3.99+0)$ & 20.42 \\
\hline$A 13 \rightarrow C(f) 3 \rightarrow C(p) 2 \rightarrow V 3$ & $(0+2.98)+(2.81+3.09)+(3.49+3.89)+(3.99+0)$ & 20.25 \\
\hline$A 2 \rightarrow C(f) 1 \rightarrow C(p) 5 \rightarrow V 2$ & $(0+3.21)+(2.93+3.57)+(3.45+3.79)+(3.21+0)$ & 20.16 \\
\hline$A 2 \rightarrow C(f) 1 \rightarrow C(p) 5 \rightarrow V 1$ & $(0+3.21)+(2.93+3.57)+(3.45+3.79)+(3.19+0)$ & 20.14 \\
\hline
\end{tabular}

Table 5. Top five chains with the highest strength

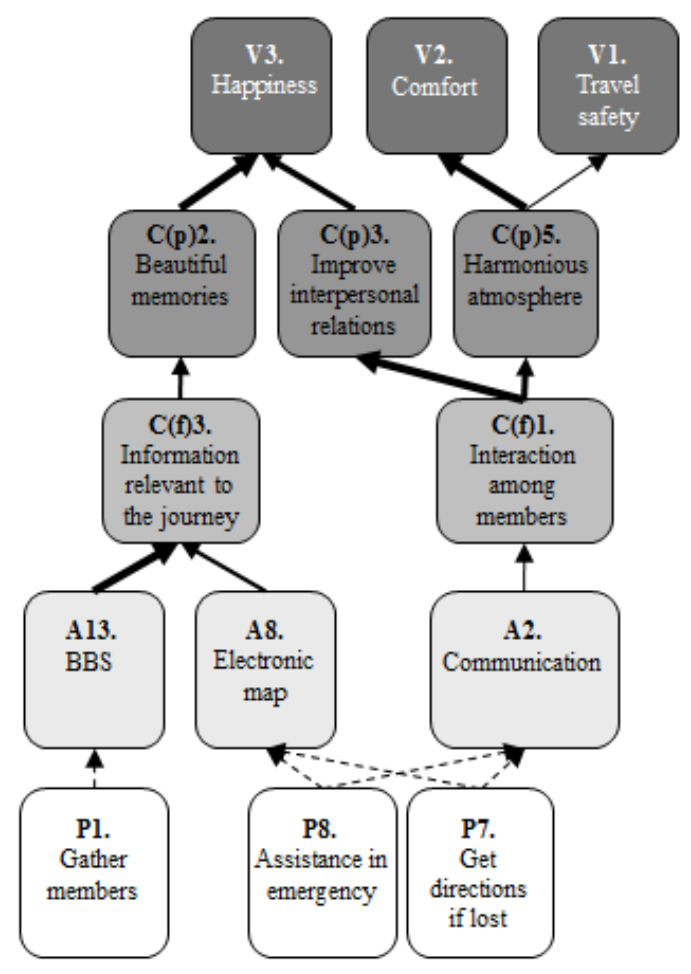

Figure 6. Streamlined Hierarchical Value Map 


\subsection{Developing the prototype}

Consumers usually have rigid, pre-existing thoughts about the features of every product and service, and it is difficult to change this mentality. Because consumers lack knowledge and demand experiences from products in a new field, there is little help derived from them regarding suggestions for the attribute levels of innovative products. Most related studies focus on the features and functionalities of products or services and the instant satisfaction brought to consumers, but they neglect the emotional benefits behind the products or services. Consequently, they fail to fully understand consumers' intangible thoughts and feelings and the forces that drive them. Therefore, when designers conduct an innovative product design, more focus should be put on "consequences" and "values" levels.

After setting up the goals by means of a streamlined HVM (see Figure 6), Mind Mapping can be used to develop a prototype. When drawing Mind Maps, there are a few essential techniques (Gelb, 1998; Mento, Martinelli \& Jones, 1999; Reed, 2005):

- Show the topic in words or pictures in the center of the paper, and then draw trunks

- On the branches extended from the trunk there should be a graph or a term

- All of the branches should form a structure of nodes with different thicknesses in the trunk and the branch

- When nothing comes to mind, a few blank lines can be added to the key terms to stimulate the user to fill them in later, if possible

- There are two ways to think: Brain Flow is thinking from one key term to another one, while Brain Bloom is thinking from one key term to many others

- Symbols, colors, or pictures can be placed onto key points to stimulate the brain to create other combinations

- The Basic Ordering Ideas principle should be used to categorize the items that appear. Mind Mapping uses thinking, selecting and understanding relevant information to help analyze decisions through the process of writing down key terms and drawing associations. 
Undertaking effective Basic Ordering Ideas is a key step in drawing Mind Maps, allowing other ideas to be organized (Buzan, 2002). For instance, if "electronic map" or "audio guide" (at the attributes level) are written on the trunk right after the start of the "electronic tour guide design" brainstorming session, the subsequent items on the branches will be limited, thus ceasing the flow of the thought process. We can use Basic Ordering Ideas as the sources of associations. This method separates the association of key terms into a few categories or levels, letting the brain think in a natural way. Once the main ideas are expressed, the sub-ideas are easily presented. The elements at the "consequences" and "values" levels in Figure 6, i.e. information, memory, interpersonal relations, atmosphere, happiness, comfort and safety, are used as the bases for association with the trunk of the Mind Map, to extend possible products or services at the branch level, and then the functions or effects provided at the sub-branch level.

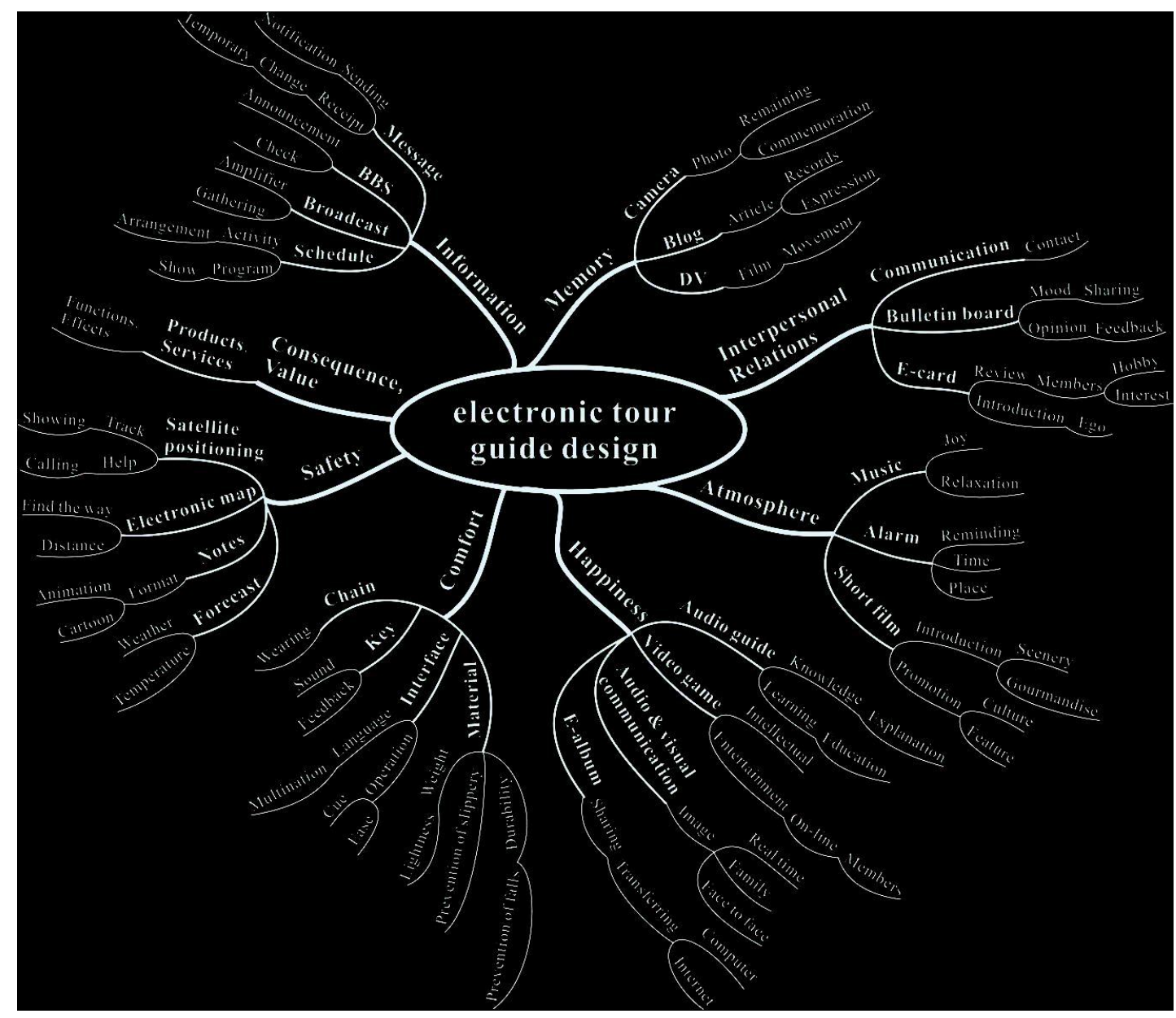

Figure 7. Mind Map for electronic tour guide design study

Designers then performed creative thinking according to their own experiences and knowledge, with the assistance of key term categorization in order to clarify the prototype of the electronic tour guide, and the results are shown in Figure 7. 
Products or services that are extended from information, atmosphere and safety can be provided between the guide and the members to increase the depth and safety of the journey, while products and services that are extended from memory, interpersonal relations, happiness and comfort can help increase satisfaction with the journey and interpersonal interaction.

\section{Discussion and limitations}

When developing a new system that is both large and complex, analysts and developers tend to collect a huge amount of general consumer data, thinking that in this way consumer demand can be known. However, such data can only reveal superficial information and has various other limits, ultimately indicating only the starting points of those factors that are most important. Therefore, when doing surveys of consumers, more attention should be paid to the nature of their needs. Many techniques have emerged to elicit these, but these mostly deal with decisions with regard to the product's functions and interface features. Understanding consumers' cognitive structures and related factors and drawing out the concept of a product's prototype based on these has received relatively little attention. This study thus combined Participant Observation, Means-End Chain and Mind Mapping to obtain pertinent information on consumers and develop the prototype of an electronic tour guide system. The contribution of this study has been to demonstrate that using EDM to elicit consumers' needs and develop prototypes of products is an effective approach. Another contribution is that the authors have altered the attribute-consequence-value model to a phenomenon-attributefunctional consequence-psychosocial consequences-value one, which can help researchers better understand consumers' behavioral intentions when using certain products.

EDM offers an electronic tour guide with a number of product or service functions that are more meaningful in terms of information, memories, interpersonal relations, atmosphere, happiness, comfort and safety. The electronic tour guide makes the GPT safer as well as more convenient and enjoyable. In addition, this system integrates relevant information and functions that can save on manpower, time and social costs. However we cannot evaluate the amount of cost savings involved. This study attached great importance to applying Participant Observations to exploring phenomena and using the Means-End Chain to understand respondents' cognitive orientations, as well as using Mind Mapping to develop a product prototype. Also, clearly defining each step and the process of information transmission can help solve conventional problems, such as undefined 
tasks and the difficulty in linking each step, which are common in empathic design operations.

Although EDM can effectively improve the development of an electronic tour guide, there are some limits to this study. First, each respondent has a different level of involvement in GPT, which may affect their five-point scale evaluations. The best testees would be people who had just come back from a GPT or often join one. Second, the authors considered only the connections between neighboring elements, like $A C(f), C(f) C(p)$ and $C(p) V$. Increasing $C(f) C(f), C(p) C(p)$ and $V V$ may reduce the limits, but the extra Associations Matrix would sharply increase the burden for the respondents and the benefits could be questionable. Third, to help each reader understand the meaning of each branch, the Mind Map in this case was expressed in key terms. When using Mind Maps to present the prototype, individuals or groups could use sketches to communicate their design ideas.

\section{Conclusions}

In the past, in order to deal with most customer demands, businesses only needed to manufacture products in large quantities and maintain sufficient inventory to ensure there was no shortage of supply. However, for today's businesses, higher flexibility is needed in both design and production processes in order to cope with dynamic market reactions. The EDM built up in this study has several advantages when dealing with this situation: First, it is based on careful observations: Human behaviors have to be followed consistently and observed precisely to acquire consumer phenomena which are closely related to the topic. Second, EDM is different from information gathered by a Means-End Chain. It requires that the respondents express the associations among elements at each level. In addition, EDM is different from survey questionnaires which use statistical techniques to explore these associations, as it collects the associations directly indicated by consumers. Third, streamlined HVM focuses on the cognitive structure of the consumer market, making the key links more obvious and thus useful for designers who are setting goals and making decisions. Fourth, Mind Mapping can effectively sort the unorganized thoughts that appear in the process of creative thinking, and create new, comprehensive associations to raise the innovative value of the prototype. Lastly, through EDM, the cognitive communication between designers and consumers can be improved, and the precision and creativity of problemsolving can be raised so that consumers' needs can be more perfectly met. To sum up, the consumer demands that are considered in the design process should be based more on what has actually been observed, rather than on designers' 
imagination. The $A-C(f)-C(p)-V$ connection network behind each phenomenon can be clearly identified step by step through the elicitation of phenomena cards and laddering interviews. The HVM, after being organized, focuses on the cognitive structure of the consumers, and it can be used in group brainstorming. A streamlined HVM can be applied to set up design goals, facilitate the progress of radiant thinking in mind mapping, and further create prototypes.

In the case study of the design of an "electronic tour guide", the authors found that the EDM was easy to handle and very useful, and this may lead to widespread future use of this model. Moreover, applying the EDM practitioners and researchers gain the following advantages. (i) Each step of EDM can be executed easily and is closely connected to the next step, and this can shorten the design time. (ii) They can accomplish classification of consumer demands and understand the relationships between each demand effectively. (iii) They can set up the design goals based on the statistics, and proceed to develop product prototypes. The methods of EDM emphasize visualizing information, and it future studies target different products or different consumers, the senses of touch, smell, hearing or taste may also be taken into consideration and used to more precisely predict and explain consumer needs. To summarize, EDM is composed of a series of systematic methods to uncover consumer demands, then transform the gathered data into design information to develop a product or service, in this case an electronic tour guide. Based on the information collected, designers can precisely identify and forecast consumers' underlying demands.

\section{References}

Ap, J., \& Wong, K. K. F. (2001). Case study on tour guiding: Professionalism, issues and problems. Tourism Management, 22(5), 551-563. http://dx.doi.org/10.1016/S0261-5177(01)00013-9

Armstrong, G., \& Kotler, P. (2000). Marketing: An introduction (5th Ed.). New Jersey: Prentice Hall.

Baxter, M. (1995). Product design: A practical guide to systematic methods of new product development. London: Chapman \& Hall.

Botschen, G., \& Hemetsberger, A. (1998). Diagnosing means-end structures to determine the degree of potential marketing program standardization. Journal of Business Research, 42(2), 151-159. http://dx.doi.org/10.1016/S0148-2963(97)00116$\underline{1}$ 
Budd, J. W. (2004). Mind maps as classroom exercises. Journal of Economic Education, 35(1), 35-46. http://dx.doi.org/10.3200/JECE.35.1.35-46

Buzan, T. (1974). Use your head. London: BBC.

Buzan, T. (2002). How to mind map: The ultimate thinking tool that will change your life. London: Thomsons.

Buzan, T., \& Buzan, B. (1996). The mind map book: How to use radiant thinking to maximize your brain's untapped potential. New York: Plume.

Chiu, C. M. (2005). Applying means-end chain theory to eliciting system requirements and understanding users perceptual orientations. Information \& Management, 42(3), 455-468. http://dx.doi.org/10.1016/j.im.2004.02.002

Chuang, M. C., Chang, C. C., \& Hsu, S. H. (2001). Perceptual factors underlying user preferences toward product form of mobile phones. International Journal of Industrial Ergonomics, 27(4), 247-258. http://dx.doi.org/10.1016/S0169$\underline{8141(00) 00054-8}$

D'Antoni, A. V., \& Zipp, G. P. (2006). Applications of the mind map learning technique in chiropractic education: A pilot study and literature review. Journal of Chiropractic Humanities, 13, 2-11.

Deszca, G., Munro, H., \& Noori, H. (1999). Developing breakthrough products: Challenges and options for market assessment. Journal of Operations Management, 17(6), 613-630. http://dx.doi.org/10.1016/S0272-6963(99)00017-0

Evans, S., \& Burns, A. D. (2007). An investigation of customer delight during product evaluation: implications for the development of desirable products. Journal of Engineering Manufacture, 221(11), 1625-1640. http://dx.doi.org/10.1243/09544054JEM786

Ferran, F. d., \& Grunert, K. G. (2007). French fair trade coffee buyers' purchasing motives: An exploratory study using means-end chains analysis. Food Quality and Preference, 18(2), 218-229. http://dx.doi.org/10.1016/j.foodqual.2005.11.001

Fotopoulos, C., Krystallis, A., \& Ness, M. (2003). Wine produced by organic grapes in Greece: Using means-end chains analysis to reveal organic buyers' purchasing motives in comparison to the non-buyers. Food Quality and Preference, 14(7), 549-566. http://dx.doi.org/10.1016/S0950-3293(02)00130-1 
Gelb, M. J. (1998). How to think like Leonardo da Vinci: Seven steps to genius every day. New York: Delacorte.

Gengler, C. E., Mulvey, M. S., \& Oglethorpe, J. E. (1999). A means-end analysis of mothers' infant feeding choices. Journal of Public Policy \& Marketing, 18(2), 172188.

Gutman, J. (1982). A means-end chain model based on consumer categorization processes. Journal of Marketing, 46(2), 60-72. http://dx.doi.org/10.2307/3203341

Gutman, J., \& Miaoulis, G. (2003). Communicating a quality position in service delivery: An application in higher education. Managing Service Quality, 13(2), 105-111. http://dx.doi.org/10.1108/09604520310466798

Hofstede, F. t., Audenaert, A., Steenkamp, J.-B. E. M., \& Wedel, M. (1998). An investigation into the association pattern technique as a quantitative approach to measuring means-end chains. International Journal of Research in Marketing, 15(1), 37-50. http://dx.doi.org/10.1016/S0167-8116(97)00029-3

Jain, D., \& Singh, S. S. (2002). Customer lifetime value research in marketing: A review and future directions. Journal of Interactive Marketing, 16(2), 34-46. http://dx.doi.org/10.1002/dir.10032

Jerrard, R. N., Barnes, N., \& Reid, A. (2008). Design, risk and new product development in five small creative companies. International Journal of Design, 2(1), 21-30.

Jordan, P. W. (1998). An introduction to usability. London: Taylor \& Francis.

Kelley, T., Littman, J., \& Peters, T. (2001). The art of innovation: Lessons in creativity from IDEO, America's leading design Firm. New York: Currency Doubleday.

Kleef, E. v., Trijp, H. C. M. v., \& Luning, P. (2005). Consumer research in the early stages of new product development: A critical review of methods and techniques. Food Quality and Preference, 16(3), 181-201. http://dx.doi.org/10.1016/j.foodqual.2004.05.012

Klenosky, D. B. (2002). The "pull" of tourism destinations: A means-end investigation. Journal of Travel Research, 40(4), 385-395. http://dx.doi.org/10.1177/0047287502040004005 
Kokotovich, V. (2008). Problem analysis and thinking tools: an empirical study of non-hierarchical mind mapping. Design Studies, 29(1), 49-69. http://dx.doi.org/10.1016/j.destud.2007.09.001

Kouprie, M., \& Visser, F. S. (2009). A framework for empathy in design: Stepping into and out of the user's life. Journal of Engineering Design, 20(5), 437-448. http://dx.doi.org/10.1080/09544820902875033

Kuisma, T., Laukkanen, T., \& Hiltunen, M. (2007). Mapping the reasons for resistance to internet banking: A means-end approach. International Journal of Information Management, 27(2), 75-85. http://dx.doi.org/10.1016/j.ijinfomgt.2006.08.006

Leonard, D., \& Rayport, J. F. (1997). Spark innovation through empathic design. Harvard Business Review, 75, 102-113.

Lofthouse, V., Bhamra, T., \& Burrow, T. (2005). A new way of understanding the customer for fibre manufacturers. International Journal of Clothing Science and Technology, 17(5), 349-360. http://dx.doi.org/10.1108/09556220510616200

Mento, A. J., Martinelli, P., \& Jones, R. M. (1999). Mind mapping in executive education: Applications and outcomes. Journal of Management Development, 18(4), 390-416. http://dx.doi.org/10.1108/02621719910265577

Miceli, G. N., Ricotta, F., \& Costabile, M. (2007). Customizing customization: A conceptual framework for interactive personalization. Journal of Interactive Marketing, 21(2), 6-25. http://dx.doi.org/10.1002/dir.20076

Nielsen, J. (1993). Usability engineering. Boston: Academic.

Olson, J. C., \& Reynolds, T. J. (1983). Understanding consumers' cognitive structures: Implications for marketing strategy. Lexington, MA: Lexington Books.

Parry, M. E. (2002). Strategic marketing management: A means-end approach. New York: McGraw Hill.

Paykoç, F., Mengi, B., Kamay, P. O., Önkol, P., Özgür, B., Pilli, O., et al. (2004). What are the major curriculum issues?: The use of mindmapping as a brainstorming exercise. Proceedings of the First International Conference on Concept Mapping, 2, 457-467. 
Pedgley, O. (2007). Capturing and analysing own design activity. Design Studies, 28(5), 463-483. http://dx.doi.org/10.1016/j.destud.2007.02.004

Phillips, J. M., \& Reynolds, T. J. (2009). A hard look at hard laddering: A comparison of studies examining the hierarchical structure of means-end theory. Qualitative Market Research: An International Journal, 12(1), 83-99. http://dx.doi.org/10.1108/13522750910927232

Pieters, R., Baumgartner, H., \& Allen, D. (1995). A means-end chain approach to consumer goal structures. International Journal of Research in Marketing, 12(3), 227-244. http://dx.doi.org/10.1016/0167-8116(95)00023-U

Protzman, K. M., \& Raval, V. (2004). Concept mapping-A learning tool for the information systems audit profession. Information Systems Control Journal, 3, 14.

Reed, W. (2005). Mind mapping for memory and creativity (in Japanese). Tokyo: Forest.

Rekom, J. v., \& Wierenga, B. (2002). Means-end relations: Hierarchies or networks? An inquiry into the (a)symmetry of means-end relations. ERIM Report Series Research in Management, ERS-2002-36-MKT.

Reynolds, T. J., \& Gutman, J. (1988). Laddering theory, method, analysis, and interpretation. Journal of Advertising Research, 28(1), 11-31.

Reynolds, T. J., \& Olson, J. C. (2001). Understanding consumer decision making: The means-end approach to marketing and advertising strategy. Mahwah, $\mathrm{NJ}$ : Lawrence Erlbaum.

Schiffman, L. G., \& Kanuk, L. L. (2000). Consumer behavior (7th Ed.). New Jersey: Prentice Hall.

Stanton, N. A., \& Young, M. S. (1999). A guide to methodology in ergonomics: Designing for human use. London: Taylor \& Francis.

Ullman, D. G. (2003). The mechanical design process (3rd Ed.). New York: McGraw Hill.

Ulwick, A. W. (2002). Turn customer input into innovation. Harvard Business Review, 80, 91-97. 
Veludo-de-Oliveira, T. M., Ikeda, A. A., \& Campomar, M. C. (2006). Discussing laddering application by the means-end chain theory. The Qualitative Report, 11(4), 626-642.

Wang, K.-C., Hsieh, A.-T., Chou, S.-H., \& Lin, Y.-S. (2007). GPTCCC: An instrument for measuring group package tour service. Tourism Management, 28(2), 361-376. http://dx.doi.org/10.1016/j.tourman.2006.04.017

Wimmer, R. D., \& Dominick, J. R. (2006). Mass media research: An introduction (8th Ed.). Belmont: Wadsworth.

Zaltman, G. (2003). How consumeres think: Essential insights into the mind of the market. Boston: Harvard Business School.

Zanoli, R., \& Naspetti, S. (2002). Consumer motivations in the purchase of organic food: A means-end approach. British Food Journal, 104(8), 643-653. http://dx.doi.org/10.1108/00070700210425930

Journal of Industrial Engineering and Management, 2012 (www.jiem.org)

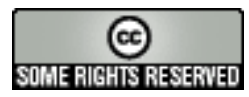

\footnotetext{
Article's contents are provided on a Attribution-Non Commercial 3.0 Creative commons license. Readers are allowed to copy, distribute and communicate article's contents, provided the author's and Journal of Industrial Engineering and Management's names are included. It must not be used for commercial purposes. To see the complete license contents, please visit http://creativecommons.org/licenses/by-nc/3.0/.
} 